\title{
Analisis Kemampuan Berfikir Kritis Siswa yang Bergaya Kognitif Reflektif dan Impulsif pada Pembelajaran Biologi melalui Model SQ3R (Survey, Question, Read, Review, Recite) dengan Media Kartu Bergambar
}

\section{Critical Thinking Analysis of Reflective and Impulsive Cognitive Civnitive Students on Biology Learning through SQ3R (Survey, Question, Read, Review, Recite) Model With Media Cards Drawing}

\author{
ARNIYAWATI ${ }^{*}$, IMAS CINTA MULYA ${ }^{1}$ \\ ${ }^{1}$ Progam Studi Pendiikan BiologiFakultas Keguruan dan Ilmu Pendidikan Universitas PGRI Ronggolawe Tuban, Indonesia \\ *Corresponding authors: nia270894@gmail.com \\ Manuscript received: ......... Revision accepted:
}

\begin{abstract}
In the curriculum of 2013 critical thinking ability is a demand that must be implemented, but in reality the process of learning in the class has not been empowering students' critical thinking skills. Then besides critical thinking another aspect to note is the aspect of cognitive style. This study aims to determine the ability of critical thinking students' cognitive reflective and impulsive style. The subjects of this study are the students of class VII A SMP Negeri 4 Tuban as many as 23 students, with 13 students with reflective cognitive style, and 10 students with cognitive impulsive style. Data collection technique in this research is MFFT (Matching Familiar Figures Test) developed by warli (2010) to know cognitive style and critical thinking test based on Ennis indicator (2011), then data about critical thinking of cognitive-style students Reflective and impulsive, was analyzed using nonparametric statistics through the Mann-Whitney test. The results in this study show the similarities between students who are reflective cognitive style with students who have cognitive impulsive style in students' critical thinking ability, because the result of the students in the same reflective style with impulsive students is because this subject is taken from the sample Class VII A where the class is the preferred class (superior). Thus it can be concluded that students' critical thinking ability with reflective cognitive style does not differ with cognitive impulsive students in Biology learning through SQ3R model (Survay, Question, Read, Recite, And Review) with pictorial card media.
\end{abstract}

Keywords: Critical thinking, reflective cognitive style, impulsive cognitive style, SQ3R (Survey, Question, Read, Recite, And Review), picture cards

\section{PENDAHULUAN}

Perkembangan ilmu pengetahuan dan teknologi yang semakin pesat menyebabkan arus informasi menjadi cepat dan tanpa batas. Hal ini berdampak langsung pada berbagai bidang kehidupan, termasuk dalam bidang pendidikan. Proses pendidikan pun dituntut untuk menyiapkan serta menghasilkan sumber daya manusia yang berkualitas agar dapat memproses informasi tersebut dengan baik dan benar (Depdiknas 2007).

Salah satu upaya dalam bidang pendidikan yang dapat dilakukan untuk mencetak SDM yang berkualitas yaitu dengan membiasakan membentuk budaya berpikir kritis pada siswa dalam proses pembelajarannya. Tujuan melatihkan kemampuan berpikir kritis kepada siswa adalah untuk menyiapkan siswa menjadi seorang pemikir kritis, mampu memecahkan masalah, dan menjadi pemikir independen, sehingga mereka dapat menghadapi kehidupan, menghindarkan diri dari indoktrinasi, penipuan, pencucian otak, mengatasi setiap masalah yang dihadapi, dan membuat keputusan dengan tepat dan bertanggung jawab.
Kenyataan di sekolah, pendidikan sains belum banyak yang berorientasi ke arah pembiasaan dan peningkatan kecakapan keterampilan berpikir tingkat tinggi (berpikir kritis). Siswa diharapkan menyerap informasi secara pasif dan kemudian mengingatnya pada saat mengikuti tes (Bassham dkk 2010). Pembelajaran yang seperti ini mengakibatkan siswa tidak memperoleh pengalaman untuk mengembangkan kemampuan berpikir kritisnya.

Berdasarkan hasil observasi yang telah dilakukan di SMP Negeri 4 Tuban melalui wawancara dengan guru IPA Biologi dan pengamatan dalam proses pembelajaran, menunjukkan proses pembelajaran dan soal-soal evaluasi yang diberikan belum berorientasi untuk mengembangkan kemampuan berpikir kritis siswa, sehingga siswa kurang dilatih untuk mengembangkan kemampuan berpikir kritis. Hal ini mengakibatkan rendahnya kemampuan berpikir kritis siswa. Siswa kesulitan menganalisis informasi yang ada, cenderung menerima apa adanya informasi yang disampaikan maupun yang tertulis dalam buku, dan pasif dalam mengajukan pertanyaan maupun menjawab pertanyaan dari permasalahan yang diajukan guru. 
Menyikapi permasalahan tersebut, terutama berkaitan dengan praktek pembelajaran Biologi di kelas dan pentingnya meningkatkan kemampuan berpikir kritis, maka upaya inovatif untuk menanggulanginya perlu segera dilakukan. Salah satu alternatif yang dapat mengatasi permasalahan tersebut adalah dengan menggunakan model pembelajaran SQ3R (survey, question, read, recite, dan review) dengan media Kartu bergambar.

Pembelajaran kooperatif tipe $S Q 3 R$ (survey, question, read, recite, dan review) merupakan model pembelajaran yang dikembangkan oleh Francis Pleasant Robinson (Kasson, 2012) dengan menekankan pada aspek pemahaman terhadap teks/bacaan, melalui penugasan kepada siswa untuk membaca bahan belajar secara seksama (Suyatno, 2009, Dalman, 2013). Penekanan model ini adalah pada keterampilan siswa dalam memahami sebuah bacaan, sehingga dapat menguasai materi pelajaran dengan baik dan secara aktif. Model pembelajaran SQ3R melalui media kartu bergambar karena siswa akan dirangasang dengan kartu bergambar yang berisi kata kunci dan menghasilkan tulisan deskripsi sebagai respon. Media kartu bergambar yang digunakan juga di buat dengan ukuran yang mudah dipegang sehingga tampak seperti permainan bagi siswa. Media kartu bergambar diklasifikan dalam media pembelajaran menurut sanjaya termasuk dalam media visual. Media kartu bergambar untuk mempermudah siswa dalam mengembangkan susunan kalimat atau mempermudah siswa dalam menuliskan karangannya.Penggunaan model SQ3R (survey, question, read, recite, dan review) dengan media Kartu bergambar ini diharapkan mampu meningkatkan gaya berfikir siswa dalam pembelajaran biologi.

Selain model dan media pembelajaran, hal yang harus diperhatiakan guru adalah karakteristik siswa yang dapat memengaruhi kemampuan berpikir kritis siswa yaitu gaya kognitif. Namun pada kenyataanya masih sangat jarang sekolah yang memperhatikan gaya kognitif yang dimiliki oleh setiap siswa.Gaya kognitif dideskripsikan sebagai cara bagaimana belajar mengolah informasi. Pada penelitian ini peneliti akan memfokuskan pada siswa SMP yang bergaya kognitif reflektif- impulsif yang dikemukakan oleh Jerome Kagan tahun 1965. Siswa yang bergaya kognitif reflktif memiliki karakteristik lambat dalam menyelesaikan masalah tetapi cermat/teliti, sehingga jawaban cenderung betul. Siswa yang bergaya kognitif impulsif memiliki karakteristik cepat menyelesaikan masalah tetapi kurang cermat/teliti sehingga jawaban cenderung salah.

Kegunaan penelitian ini bagi siswa, yaitu 1) meningkatkan aktifitas siswa dalam proses belajar mengajar; 2) Untuk mengetahui kemampuan berfikir kritis siswa yang bergaya kognitif reflektif dan impulsif.

\section{METODE PENELITIAN}

Penelitian ini berbentuk penelitian Deskriptif Eksploratif yang bertujuan untuk mendeskripsikan kemampuan berfikir kritis siswa pada pembelajaran biologi melalui model pembelajaran SQ3R (survey, question, read, recite, dan review) dengan media Kartu bergambar di tinjau dari gaya kognitif reflektif dan kognitif impulsif.

Penelitian deskriptif ini dilaksanakan di SMP Negeri 4 Tuban tahun ajaran 2017/2018. Subjek penelitian ini adalah anak didik kelas VII A SMP NEGERI 4 TUBAN yang berjumlah 23 siswa, dengan rincian 13 siswa yang bergaya kognitif reflektif, dan 10 siswa yang bergaya kognitif impulsif.

Instrumen dalam penelitian ini adalah tes MFFT untuk mengukur gaya kognitif reflektif -impulsif dan mengukur tes untuk kemampuan berfikir kritis siswa. Melalui model pembelajaran SQ3R dengan media kartu bergambar, pada pokok bahasa pencemaran lingkungan. Penelitian ini mengacu pada Ennis dalam Bahriah (2011) yang menguraikan kategori kemampuan berfikir kriris yang akan disajikan pada Tabel 1

Tabel 1. Kategorisasi Kemampuan Berpikir Kritis

\begin{tabular}{|c|c|c|c|}
\hline $\begin{array}{l}\mathrm{N} \\
\mathrm{o}\end{array}$ & Indikator & Indikator 0prasional & Skor \\
\hline & $\begin{array}{l}\text { Mengide } \\
\text { ntikasi }\end{array}$ & $\begin{array}{c}\text { Mendefinisikan masalah sangat } \\
\text { jelas }\end{array}$ & 4 \\
\hline & kata & Mendefinisikan masalah & 3 \\
\hline & kunci & dengan jelas & \\
\hline & permasal & Mendefinisikan masalah & 2 \\
\hline & & Mendefinisikan masalah tidak & \\
\hline & & jelas & 1 \\
\hline \multirow[t]{2}{*}{2} & Mendefi & Mengidentifikasi masalah & 4 \\
\hline & nisikan & utama dengan sangat akurat & \\
\hline & masalah & $\begin{array}{l}\text { Mengidentifikasi masalah } \\
\text { utama dengan akurat }\end{array}$ & 3 \\
\hline & & Mengidentifikasi masalah & 2 \\
\hline & & $\begin{array}{l}\text { utama dengan kurang akurat } \\
\text { Mengidentifikasi masalah }\end{array}$ & \\
\hline & & utama dengan tidak akurat & 1 \\
\hline \multirow{7}{*}{$\begin{array}{l}3 \\
.\end{array}$} & Teknik & Menyikapi masalah sangat & 4 \\
\hline & menyika & objektif & \\
\hline & pi & Menyikapi masalah dengan & 3 \\
\hline & & $\begin{array}{l}\text { objektif } \\
\text { Menyikapi masalah kurang }\end{array}$ & \\
\hline & & objektif & 2 \\
\hline & & Menyikapi masalah tidak & \\
\hline & & objektif & 1 \\
\hline \multirow[t]{6}{*}{4} & Menentu & Mengidentifikasi, berempati, & 4 \\
\hline & $\begin{array}{c}\text { kan } \\
\text { sudut }\end{array}$ & $\begin{array}{l}\text { adil, dan menghargai seluruh } \\
\text { sudut pandang yang relevan }\end{array}$ & \\
\hline & pandang & Mengidentifikasi, berempati, & \\
\hline & $\begin{array}{l}\text { terhadap } \\
\text { masalah }\end{array}$ & $\begin{array}{l}\text { adil terhadap seluruh sudut } \\
\text { pandang yang relevan }\end{array}$ & 3 \\
\hline & & $\begin{array}{l}\text { Mengidentifikasi, berempati, } \\
\text { terhadap seluruh sudut pandang }\end{array}$ & \\
\hline & & $\begin{array}{c}\text { yang relevan } \\
\text { Mengidentifikasi sudut } \\
\text { pandang yang kurang jelas }\end{array}$ & 2 \\
\hline
\end{tabular}




\begin{tabular}{cccc}
\hline 5 & Penarika & Menarik kesimpulan berupa & 4 \\
kesimpul & solusi pemecahan masalah & \\
an & yang relevan, berlandasan & \\
& argumen yang rasional, kreatif, & \\
& dan bijaksana & \\
& Menarik kesimpulan berupa & \\
& solusi pemecahan masalah & 3 \\
& yang relevan, berlandasan & \\
& argumen yang rasional, dan & \\
& kreatif \\
& Menarik kesimpulan berupa & \\
& solusii pemecahan masalah & 2 \\
& yang relevan, berdasarkan & \\
& argumen yang rasional & \\
& Tidak mampu menarik & \\
& kesimpulan dan menghasilkan & 1 \\
& solusi yang relevan &
\end{tabular}

Prosedur penelitian ini dilakukan 2 tahap, yaitu:

Yang pertama, tahap Persiapan;a) pada tahap ini penelitian meminta surat ijin dan melakukan observasi untuk mengetahui kondisi dan permasalahan sekolah yang akan di teliti; b) menyiapkan instrumen tes MFFT untuk menentukan gaya kognitif reflektif-impulsif yang dimiliki siswa; c) peneliti menyiapkan rencana pelaksanaan pembelajaran (RPP), silabus yang sesuai dengan materi yang akan diajarkan yaitu tentang pencemaran lingkungan; d) menyiapkan media pembelajaran yaitu media kartu bergambar; e) menyusun instrumen penelitian berupa soalsoal yang akan diuji dengan membatasi materi terlebih dahulu. Menyusun kisi-kisi soal, menentukan jumlah soal yang akan diberikan; f) menentukan kelas yang akan digunakan untuk penelitian, yaitu kelas VII A. Yang kedua, tahap pelaksanaan, tahap pelaksanaan ini dilakukan di SMP Negeri 4 Tuban dengan menggunakan 1 kelas yaitu kelas VII A. Pertemuan dilakukan 2 kali pertemuan dengan alokasi waktu setiap pertemuan 2 x 40 menit. Dalam penelitian ini menggunakan model SQ3R (survey, question, read, recite, dan review) dengan media Kartu bergambar. Untuk mengetahui hasil belajar dan kemampuan berfikir kritis siswa di berikan post-test di akhir pembelajaran; a) guru memberikan tes MFFT kepada siswa untuk mengetahui gaya kognitif reflektif-impulsif yang dimiliki masing-masing siswa. Pelaksanaan tes dilakukan diluar jam pelajaran; b) guru melaksanakan pembelajaran sesuai RPP menggunakan model pembelajaran SQ3R (survey, question, read, recite, dan review ) dengan media kartu bergambar pada materi pencemaran lingkungan; c) guru memberikan tes kepada siswa untuk memperoleh informasi kemampuan berfikir kritis siswa yang bergaya kognitif refrektif dan siswa yang bergaya kognitif impulsif sesudah pembelajaran; d)Guru memeriksa hasil pekerjaan siswa yang bergaya kognitif reflektif dan bergaya kognitif impulsif.

\section{HASIL DAN PEMBAHASAN}

Berdasarkan penelitian yang telah dilaksanakan pada bulan April 2017 di SMP Negeri 4 Tuban pada pokok bahasan pencemaran lingkungan. Data yang sudah dikumpulkan dalam penelitian ini berasal dari tes gaya kognitif reflektif dan impulsif MFFT (Matching Familiar Figure Test) yang telah dirancang dan dikembangkan oleh Warli (2010) dan juga tes berpikir kritis yang mengacu pada indikator yang dikemukakan oleh Ennis (1985). Berdasarkan hasil tes gaya kognitif reflektif dan impulsif dan juga tes berpikir kritis tersebut diperoleh data sebagai berikut:

\section{Deskripsi Gaya Kognitif Siswa}

Pada penelitian ini, pemilihan subjek dipilih dari siswa kelas VII A SMP Negeri 4 Tuban tahun ajaran 2017-2018 dengan kegiatan pengukuran gaya kognitif reflektif dan impulsif.. Pada tes Matching Familiar Figure Test (MFFT) terdapat 13 item soal bergambar dengan ditambah 2 item soal untuk percobaan. Pada setiap item terdapat satu gambar standar (baku) dan 8 gambar variasi, di antara 8 gambar variasi ada 1 gambar yang sama dengan gambar standart. Tugas siswa adalah memilih salah satu gambar variasi yang sama dengan gambar standart.

Dalam pengukuran ini hal-hal yang perlu dicatat dalam tes Matching Familiar Figure Test (MFFT) ini adalah ; a) jarak waktu antara stimulus dan respon pertama yang diberikan siswa (t), dan b) frekuensi jawaban siswa sampai diproleh jawaban betul (f). Penentuuan gaya kognitif siswa dihitung berdasarkan titik tengah atau median data jarak waktu (t) dan titik tengah atau median data frekuensi jawaban siswa sampai betul (f). Dari kedua data tersebut (median waktu dan frekuensi menjawab) digunakan sebagai batas penentuan siswa yang mempunyai karastristik atau gaya reflektif ataupun gaya impulsif. Kemudian dengan kedua data tersebut (median waktu dan frekuensi menjawab) ditarikkan garis sejajar dengan sumbu $\mathrm{t}$ dan sumbu $\mathrm{f}$, sehingga akan membentuk 4 kelompok siswa.

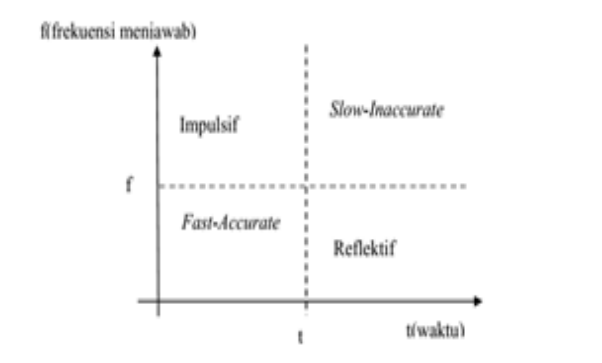

Gambar 1. Matching Familiar Figure Test

Setelah pengukuran gaya kognitif peneliti mendapatkan rangkuman hasil pengukuran gaya kognitif yang disajikan pada Tabel 2

Tabel 2. Tipe Gaya Kognitif Siswa

\begin{tabular}{|c|c|c|c|c|c|}
\hline \multirow[t]{2}{*}{. } & \multicolumn{4}{|c|}{ Gaya Kognitif } & \multirow{2}{*}{$\begin{array}{c}\text { Jumlah } \\
\text { Seluruh } \\
\text { Siswa }\end{array}$} \\
\hline & Reflektif & Impulsif & $\begin{array}{c}\text { Cepat } \\
\text { Akurat }\end{array}$ & $\begin{array}{l}\text { Lamba } \\
\text { t tidak } \\
\text { akurat }\end{array}$ & \\
\hline Jumlah & 13 & 10 Siswa & 7 & 5 & 35 \\
\hline $\begin{array}{c}\text { Presentas } \\
\mathrm{e}\end{array}$ & $\begin{array}{c}\text { Siswa } \\
37 \%\end{array}$ & $29 \%$ & $\begin{array}{c}\text { Siswa } \\
20 \%\end{array}$ & $\begin{array}{l}\text { Siswa } \\
14 \%\end{array}$ & $\begin{array}{l}\text { siswa } \\
100 \%\end{array}$ \\
\hline
\end{tabular}

Bedasarkan tabel 2 jumlah siswa reflektif ada 13 siswa (37\%) sedangkan siswa impulsif ada 10 siswa (29\%). Ini menunjukkan bahwa proporsi siswa yang memiliki 
karaktristik reflektif dan impulsif lebih besar yaitu $66 \%$ sisanya yaitu 36\% adalah siswa yang memiliki cepat dan tepat/akurat dalam menjawab atau lambat dan kurang tepat/akurat dalam menjawab. Hasil ini sesuai dengan beberapa peneliti sebelumnya, penelitian Warli (2010) proporsi anak reflektif-impulsif $73 \%$, penelitian Reuchlin (2005) proporsi anak reflektif- impulsif 70\%, penelitian Rozencwajg \& Corroyer 2005) proporsi anak reflektifimpulsif 76,2\%. Dari data tersebut diproleh 6 subjek.

Tabel 3 Subjek Penelitian Gaya Kognitif dan Impulsif

\begin{tabular}{ccc}
\hline No & $\begin{array}{c}\text { Inisial Nama } \\
\text { Subjek }\end{array}$ & Jenis gaya kognitif \\
\hline 1. & NSA & Reflektif \\
2. & MMP & Reflektif \\
3. & FIS & Reflektif \\
4. & MAH & Impulsif \\
5. & NDA & Impulsif \\
6. & TMSAR & Impulsif \\
\hline
\end{tabular}

Pemilihan subjek penelitian diatas dipilih dari 3 siswa dari masing-masing kelompok, yaitu 3 siswa bergaya kognitif reflektif dan 3 siswa bergaya kognitif impulsif dengan pertimbangan siswa impulsif dipilih dari siswa yang memiliki catatan waktu sedikit dan frekuensi menjawab banyak, sedangkan siswa reflektif dipilih dari siswa yang catatan waktu banyak dan frekuensi menjawab sedikit. Hal ini bertujuan agar subjek penelitian benarbenar impulsif atau reflektif.

Data hasil pengukuran gaya kognitif dihitung median baik untuk catatan waktu atau frekuensi menjawab. Median dari catatan waktu dan frekuensi menjawab akan digunakan sebagai batas penentuan siswa yang mempunyai karaktristik impulsif dan reflektif.

\section{Hasil Tes Berpikir kritis Siswa Reflektif dan Impulsif}

Tes kemampuan berfikir kritis diberikan kepada 35 siswa kelas VII A SMP Negeri 4 Tuban yang mengerjakan soal tes yang berjumlah 7 butir soal uraian. Data hasil pekerjaan 35 siswa tersebut diperiksa akan tetapi hanya jawaban tertulis 6 siswa yang di analisis dengan melihat nilai yang diperoleh. Berikut ini akan di sajikan nilai hasil tes kemampuan berfikir kritis siswa dalam tabel .

Tabel 4 Data Hasil Tes Kemampuan Berfikir Kritis

\begin{tabular}{ccc}
\hline No. & Reflektif & Impulsif \\
\hline 1. & 75 & 75 \\
2. & 96 & 64 \\
3. & 69 & 75 \\
4. & 36 & 82 \\
5. & 79 & 57 \\
6. & 67 & 64 \\
7. & 82 & 71 \\
8. & 96 & 64 \\
9. & 75 & 78 \\
10. & 78 & 71 \\
11. & 96 & \\
12. & 75 & \\
13 & 86 & \\
\hline
\end{tabular}

\section{Analisis Data Hasil Penelitian}

Untuk menguji kemampuan berfikir kritis siswa yang bergaya kognitif impulsif dan kognitif reflektif. Digunakan uji statistik non parametrik dengan uji mannwhitney. Perumusan hipotesis uji kesamaan siswa yang bergaya kognitif impulsif dan kognitif reflektif adalah sebagai berikut:

HO : Tidak terdapat perbedaan kemampuan berfikir kritis siswa yang bergaya kognitif reflektif dan kognitif impulsif. H1: terdapat perbedaan kemampuan berfikir kritis siswa yang bergaya kognitif reflektif dan kognitif impulsif.

Tabel 3. Hasil Uji Statistik

\begin{tabular}{|c|c|}
\hline & nilai berfikir kritis \\
\hline Mann-Whitney U & 34.000 \\
Wilcoxon W & 89.000 \\
Z & -1.937 \\
Asymp. Sig. (2- & .053 \\
tailed) & $.057^{\mathrm{a}}$ \\
Exact Sig. [2*(1- \\
tailed Sig.)] \\
\multicolumn{2}{|c|}{ a. Not corrected for ties. } \\
b. Grouping Variable: gaya kognitif
\end{tabular}

Hipotesis yang akan diuji adalah tidak ada pembedaan kemampuan berfikir kritis siswa yang bergaya kognitif impulsif dan kognitif reflektif. Hipotesis yang dirumuskan adalah sebagai berikut:

H0: Tidak terdapat perbedaan kemampuan berfikir kritis siswa yang bergaya kognitif reflektif dan kognitif impulsif.

H1: Terdapat perbedaan kemampuan berfikir kritis siswa yang bergaya kognitif reflektif dan kognitif impulsif.

Hipotesis statistiknya adalah:

H0: $M e 1-M e 2=0$

$\mathrm{H} 1: M e 1-M e 2 \neq 0$

Dari Tabel 3.4 dapat diketahui statistik uji MannWhitney adalah $\mathrm{T}$ sebesar 34 . Karena $n 1=13$ dan $n 2=10$, keduanya lebih kecil dari 20 maka kita dapat menggunakan tabel kuantil-kuantil statistik uji Mann- Whitney.

Sehingga kriteria pengambilan keputusan adalah jika T $<\mathrm{w} \alpha / 2$ atau $\mathrm{T}>\mathrm{w} 1-\alpha / 2 \mathrm{H} 0$ di tolak. Jika sebaliknya maka H0 ditrima.

Dengan melihat tabel kuantil-kuantil statistik uji MannWhitney untuk $\alpha=0,05, \mathrm{n} 1=13$ dan $\mathrm{n} 2=10$, (lampiran kuartil-kuartil statistik) maka kita dapatkan $w \alpha / 2=$ $\mathrm{w} 0,05 / 2=\quad w 0,025=34$. Sedangkan $w 1-\alpha / 2=w 1-$ $0,025=\mathrm{w} 0,975$ dapat dicari dengan rumus $\mathrm{w} 1-\alpha / 2=\mathrm{n} 1 \mathrm{n} 2-$ $\mathrm{w} \alpha / 2$

Maka $w 0,975=13(10)-34=130-34=96$

Karena $w \alpha / 2=\mathrm{T}<\mathrm{w} 1-\alpha / 2$ yaitu $34=34<96$ maka keputusanya adalah H0 ditrima, jika kita melihat Asymp. Sig. (2 -tailed) yang sebesar 0,53>0,05.maka keputusan yang kita dapatkan juga sama yaitu H0 ditrima. Jadi kesimpulanya kemampuan berfikir kritis siswa yang 
bergaya kognitif reflektif dan siswa yang bergaya kognitif impulsif tidak ada perbedaan.

\section{PEMBAHASAN}

\section{Hasil Analisis Berpikir Kritis Siswa Gaya Kognitif Reflektif}

Pada bagian ini akan dibahas tentang kemampuan berpikir kritis siswa melalui model pembelajaran SQ3R (survey, question, read, review, recite) dengan media kartu bergambar ditinjau dari gaya kognitif reflektif dan impulsif kelas VII-A SMP Negeri 4 Tuban. Telah dipilih siswa yang menjadi subjek penelitian untuk kelompok berpikir kritis siswa gaya reflektif. Hasil tes berpikir kritis siswa dianalisis berdasarkan indikator berpikir kritis yang dikemukakan oleh Ennis (1985) yaitu, mengidentifikasi kata kunci permasalahan. Mengidentifikasi masalah, teknik menyikapi masalah, menentukan sudut pandang terhadap masalah, penarikan kesimpulan. Berikut adalah hasil tes subjek penelitian berpikir kritis siswa reflektif disajikan dalam gambar 2 .

Gambar 2. Hasil tes subjek penelitian berpikir kritis siswa reflektif.

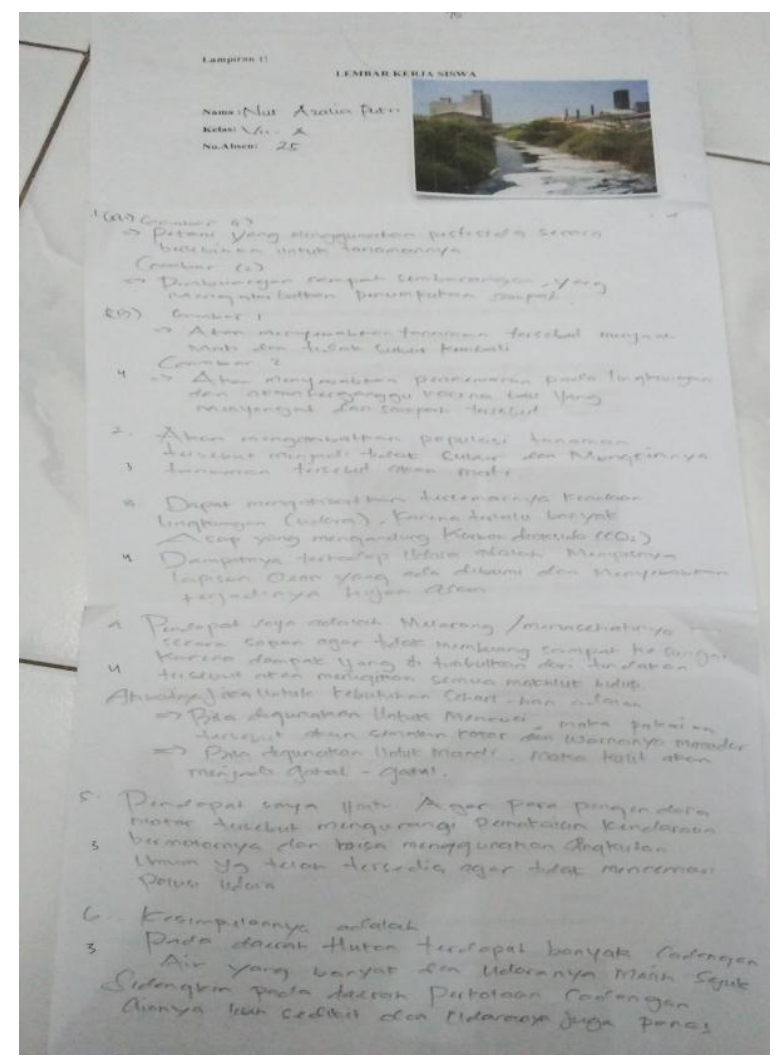

Berdasarkan dari hasil tes subjek penelitian berpikir kritis siswa gaya kognitif reflektif diatas bisa dilihat bahwa anak reflektif mampu menjawab 7 soal dengan sangat baik, jawaban yang diberikan cenderung panjang dan sangat detail. Ketika diperhatikan saat proses mengerjakan soal tes yang diberikan siswa selalu berpikir terlebih dahulu sebelum menjawab. siswa mencoba berkali-kali pada lembar coretan dan ketika sudah yakin dengan jawabannya siswa langsung menulis hasilnya di lembar jawaban.
Kejadian tersebut sesuai dengan Philip yang menyatakan bahwa siswa reflektif mempertimbangkan banyak alternatif sebelum merespon sehingga tinggi kemungkinan bahwa respon yang diberikan adalah benar. Begitu pula, Nasution menjelaskan bahwa siswa yang reflektif mempertimbangkan segala alternatif sebelum mengambil keputusan dalam situasi yang tidak mempunyai penyelesaian masalah. Siswa reflektif selalu mengambil waktu untuk berpikir dan merenung sebelum menjawab pertanyaan maupun mengerjakan tes yang diberikan. Waktu yang relatif lama saat menyelesaikan masalah ini jugalah yang menjadi alasan anak reflektif relatif kecil dalam membuat kesalahan karena menggunakan waktu untuk berpikir kritis mendalam dalam menjawab soal. Kemudian jika dilihat dari proses pembelajaran dikelas siswa reflektif memiliki rasa ingin tahu yang tinggi sehingga dia selalu mengajukan pertanyaan.

Hasil Analisis Berpikir Kritis Siswa Gaya Kognitif Impulsif

Pada bagian ini akan dibahas tentang kemampuan berpikir kritis siswa melalui model pembelajaran SQ3R (survey, question, read, review, recite) dengan media kartu bergambar ditinjau dari gaya kognitif reflektif dan impulsif kelas VII-A SMP Negeri 4 Tuban. Telah dipilih siswa yang menjadi subjek penelitian untuk kelompok berpikir kritis siswa gaya impulsif. Hasil tes berpikir kritis siswa dianalisis berdasarkan indikator berpikir kritis yang dikemukakan oleh Ennis (1985) yaitu. mengidentifikasi kata kunci permasalahan. Mengidentifikasi masalah, teknik menyikapi masalah, menentukan sudut pandang terhadap masalah, penarikan kesimpulan. Berikut adalah hasil tes subjek penelitian berpikir kritis siswa impulsif disajikan dalam gambar 3 .

Gambar 3. Hasil tes subjek penelitian berpikir kritis siswa impulsive

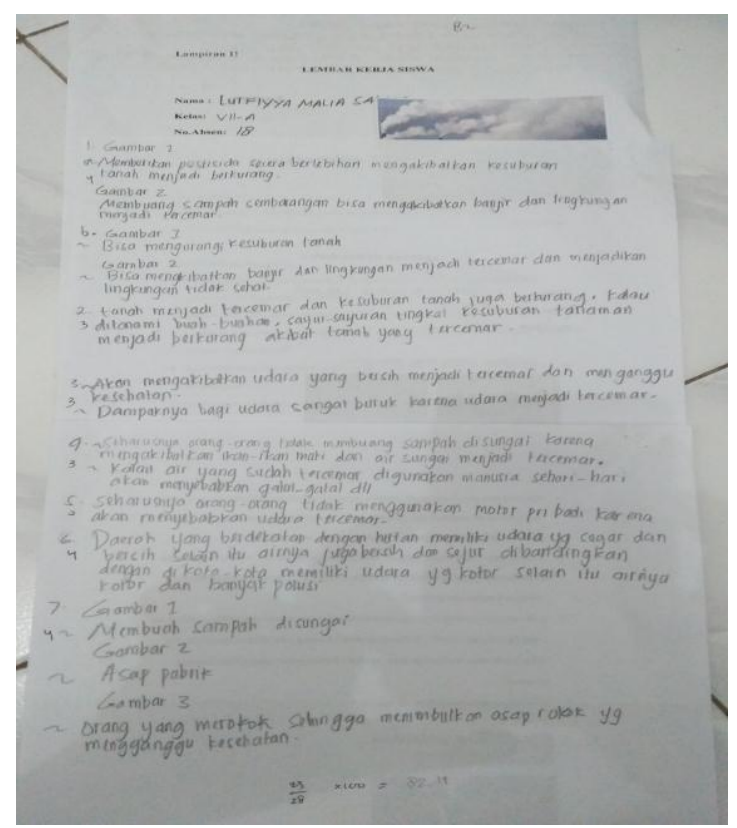


Berdasarkan dari hasil tes subjek penelitian berpikir kritis siswa gaya kognitif impulsif diatas bisa dilihat bahwa anak impulsif mampu menjawab 7 soal cukup baik, jawaban yang diberikan juga cenderung banyak sama halnya seperti anak yang bergaya kognitif impulsif, dia memberikan jawaban yang sama panjang dan banyak mungkin sesuai dengan permintaan soal. Tetapi kemampuan berpikir kritis cenderung lebih rendah, tidak berpikir mendalam. Jika diperhatikan Saat mengerjakan tes, siswa impulsif menulis semua ide maupun rencana yang ada dalam pikirannya di lembar jawaban sehingga proses menjawab soal cenderung cepat. Bahkan ketika sudah selesai mengerjakan siswa langsung mengumpulkan hasil pekerjaannya dan tidak mengkoreksi jawabannya terlebih dahulu. karena cepat dalam menjawab itulah yang membuat siswa impulsif dapat mengumpulkan jawabannya dengan cepat pula. Hal tersebut tidak sejalan dengan pernyataan Kagan (1965) bahwa anak impulsif memiliki karakteristik cepat dalam menjawab masalah, tetapi tidak cermat sehingga jawaban masalah cenderung salah, mungkin dikarenakan subjek penelitian di lakukan di kelas VII A yang merupakan kelas unggulan.

\section{KESIMPULAN}

Bedasarkan hasil analisis data dan pembahasan hasil penelitian yang telah dilakukan peneliti pada ke 2 subjek kelompok penelitian, diproleh kesimpulan analisis berfikir kritis siswa melalui model pembelakaran SQ3R (survey, question, read, recite, dan review) dengan media Kartu bergambar di tinjau dari gaya kognitif reflektif dan impulsif kelas VII A SMP Negeri 4 Tuban tahun ajaran 2017/2018 pada pokok bahasan pencemaran lingkungan adalah kemampuan berfikir kritis siswa yang bergaya reflektif maupun impulsif mempunyai rata-rata yang sama atau tidak ada perbedaan dikarenakan pada penelitian ini mengambil populasi pada kelas unggulan pada pembelajaran biologi melalui model SQ3R (survey, question, read, recite, dan review) dengan media Kartu bergambar. Oleh karena itu peneliti menyarankan agar guru hendaknya memperhatikan gaya kognitif siswa dalam proses pembelajaran dan perlu di adakan penelitian lebih lanjut mengenai presentase masing-masing gaya kognitif siswa untuk dijadikan pedoman dalam menyusun kurikulum.

\section{UCAPAN TERIMAKSIH}

Dengan terselesainya penelitian ini, penulis mengucapkan trimakasih yang sedalam-dalamnya kepada:

1. Allah SWT. Atas limpahan karunia dan hidayahnya sehingga penulis dapat melaksanakan dan menyelesaikan penelitian.

2. Ibu Imas Cinta Mulya, M.Si selaku dosen pendidikan Biologi atas bimbinganya, arahan dan koreksianya selama penyusunan dan penulisan penelitian.
3. Kedua orang tua saya yang telah membantu dan mendukung saya dalam mengerjakan penelitian ini, serta kakak-kakak saya yang telah selalu memotivasiku

\section{DAFTAR PUSTAKA}

Arikunto, S. 2010. Penelitian Tindakan Kelas. Yogyakarta: Aditya Media.

Djamarah, 2006. Strategi Belajar Mengajar. Jakarta: Rineka Cipta

Faricha A. F., Nurchasanah, Nurhadi. 2012. Pengaruh Strategi SQ3R Terhadap Kemampuan Membaca Kritis Siswa Kelas VII SMP N 3 Malang. Universitas Negeri Malang.

Himmatul, U. 2015. Hubungan Gaya Kognitif Dengan Kemampuan Pemecahan Masalah Matematika Siswa. Jurnal Konseling Gusjigang. Vol. 1 No. 2.

Kagan, Jerome dan Kogan, Nothan (1970) Individual Variation in Cognitive Process. Dalam Mussan, P. (Edt.) Carmichael's Manual of Child Psychology (3 rd ed. Vol. 1) Wiley New York.

Ketut, R. 2012. Pengaruh Model Pembelajaran Berbasis Masalah Terhadap Ketrampila Berfikir Kritis Ditinjau Dari Gaya Kognitif Siswa. Program Studi Pendidikan IPA, Universitas Pendidikan Ghanesa.

Nasriadi, A. 2016. Berfikir Reflektif Siswa SMP Dalam Memecahkan Masalah Matematika Ditinjau Dari Pemebeda Gaya Kognitif. Dosen Prodi Pendidikan Matematika, STKIP Bina Bangsa Getsempena, Email: ahmad@stkipgetsempena.ac.id. (Volume III. Nomor 1. Tahun 2016

Ni Putu C. P., I Gusti N. J., Ni Wayan A. 2016. Pengaruh Make a Match Terhadap Kemampuan Berfikir Kritis Ips Ditinjau Dari Gaya Kognitif Siswa Kelas IV. eJournal PGSD Universitas Pendidikan Ganesha Jurusan PGSD (Vol. 4 No. 1 Tahun 2016.

Prabati, Mega, N. 2011. Pengaruh Penggunaan Pembelajaran Kontekstual Dengan Teknik SQ3R Terhadap Peningkatan Kemampuan Pemahaman Dan Berfikir Kritis Matematik Siswa SMA. S2 thesis, Universitas Pendidikan Indonesia.

Sudia , Muh . 2012 ,Profil metakognisi Siswa yang bergaya Kognitif Implusif dan gaya Reflektif dalampemecahan masalahdengan perbedaanGender. Semarang

Warli, 2010. "profil Kreativitas siswa Yang Bergaya Kognitif Reflektif dan Siswa Yang Bergaya Kognitif Impulsif Dalam Memecahkan Geometri”. Disertasi Doktor, Unesa Surabaya.

Warsono, 2012. Pembelajaran Aktif Teori dan Asesmen. Bandung: Remaja Rosdakarya.

Woolfolk, Anita E. 1998. Educational Psychology. Singapore: Allyn and Bacon. 